\title{
Effects of Modified Cervical Exercise on Respiratory Functions in Smartphone Users with Forward Head Posture
}

\author{
Yong-Soo Kong, Yu-Mi Kim, Je-Myung Shim \\ Department of Physical Therapy, College of Health and Science, Kangwon National University, Chuncheon, Korea
}

Purpose: This study was conducted to investigate the effects of modified cervical exercise on respiratory functions in smartphone users with forward head posture.

Methods: Thirty-three smartphone users with forward head posture participated in this study. Subjects were divided into three groups that performed modified cervical exercise one time a day (A group), two times a day (B group), and three times a day ( $\mathrm{C}$ group). All subjects performed the exercise for four weeks, during which time respiratory functions were measured.

Results: There were significant differences in respiratory functions such as forced vital capacity, forced expiratory volume at one second, and maximal voluntary ventilation in the $\mathrm{C}$ group after four weeks $(\mathrm{p}<0.05)$. Moreover, the forced vital capacity differed among groups, and the post hoc test revealed a significant difference between $A$ group and $C$ group $(p<0.05)$.

Conclusion: The results of this study confirmed that modified cervical exercise improved respiratory functions in smartphone users with forward head posture. These findings indicate that smartphone users with forward head posture should perform modified cervical exercise to build correct posture and respiratory functions.

Keywords: Smartphone, Respiratory function, Posture

\section{서 론}

우리나라의 최근 이동전화 가입자 수는 2015년 3월 기준으로 약 5,733 만 명이었으며, 그 중 스마트폰 가입자 수는 약 4,126 만 명에 이르 렀다. 최근 스마트폰 사용량의 증가로 장시간 머리를 앞으로 내미는 자세에 노출되면서 일자 목 환자들이 늘고 있으며, 국민건강보험공단 이 발표한 자료에 의하면 목과 어깨, 팔에 통증을 호소하는 목 디스 크 환자가 2007년 57만명에서 2011년 78만명으로 증가하였으며, 태블 릿과 스마프폰의 보급이 활성화되기 시작한 2009년에서 2013년 까지 5년 사이에 목 디스크(경추추간판장애, M50)환자가 무려 $30.8 \%$ 증가 한 것으로 나타났다. 그 중 20 대 환자의 증가율이 가장 높다고 하였으 며, 젊은층의 목 디스크 환자 급증은 스마트폰의 장시간 사용이 원인 일 것이라고 하였다. ${ }^{2}$

스마트폰의 대중화로 인하여 장시간의 작업은 목과 어깨의 비정상 적인 정렬을 더욱 증가시킬 가능성이 높으며, ${ }^{3}$ 스마트폰을 오랜 시간 사용하게 되면 전방머리자세(forward head posture, FHP)나 구부정한 자세(slouched posture)와 같은 부적절한 자세를 유발할 수 있다. 상대

Received Sep 13, 2016 Revised Sep 27, 2016

Accepted Oct 14, 2016

Corresponding author Je-Myung Shim

E-mailsjm7897@hanmail.net
적 보상작용으로 인한 각 신체의 바른 자세는 우리 몸을 효율적이고 효과적으로 사용할 수 있지만, 잘못된 자세는 몸에 비효율적인 균형 상태로 비정상적인 스트레스를 증가시킨다. 전방머리자세는 상부 목 뼈관절과 고리뒤통수관절의 보상으로 과도한 폄을 유발하여 뒤통 수 근육이 단축되어 목과 어깨 근육의 비정상적인 변화가 유발된다. ${ }^{6}$ 또한, 전방머리자세의 증가는 목에 통증이 있는 환자의 호흡근력 감 소와 상관관계가 있으며, 근육의 약화와 관절가동 범위의 감소 등을 초래한다. ${ }^{78}$ Quek 등9은 두부 전방전위자세가 등뼈부위의 뒤굽음을 증가시키고, 목뼈부위의 관절가동 범위를 감소시킨다고 하였다.

호흡은 근 골격계와 신경계의 기능이 협동하는 복합적인 기능이 다. 전방머리자세는 목뼈와 등뼈의 구조를 비정상적으로 변화시켜 가슴우리와 호흡기능의 변화를 야기할 수 있으며, 만성 목 통증을 가진 환자는 최적의 허파기능을 가지기 힘들고, 목뼈와 등빼 근육의 기능 장애는 호흡 기능의 장애와 관련이 있다고 주장하였다. ${ }^{10}$ Perri 와 Halford" ${ }^{11}$ 는 전방머리자세는 호흡기능이 떨어지는 환자들이 그들 의 환기 기능과 호흡기능을 증가시키기 위해 만드는 보상적인 자세라 고 하였으며, 또한 두부 전방전위 자세가 있는 사람들은 두부 전방전 
위 자세가 아닌 사람들에 비해 호흡기능이 감소한다고 하였다.12 최근 Dimitriadis 등 10 은 잘못된 자세와 관련하여 호흡 운동의 중요성을 부 각시켰으며, Kapreli 등은 잘못된 자세로 인한 호흡 기능의 관계를 중 요하게 고려해야 한다고 하였다. 또한, Silveria 등'13의 연구에서는 잘못 된 자세로 인해 호흡기능이 변화될 수 있기 때문에 호흡기 질환자의 자세가 부적절하게 바뀌게 되면 그들의 호흡기능을 더욱 악화시킬 수 있다고 하였다. 따라서 전방머리자세의 개선을 통하여 이러한 문 제점을 해결할 수 있는데, 많은 연구에서 자세정렬을 위해 약화된 근 육은 강화시키고, 짧아진 근육은 스트레칭을 적용시키는 치료적 접 근이 필요하다고 제시하였다.14

멕켄지(McKenzie) 운동은 반복적인 운동을 통해 환자 스스로 자 가-치료 운동을 하며 가동운동, 도수교정, 환자교육을 포함하며 폄 운동에 중점을 두는 것이다. ${ }^{15} \mathrm{Jung}^{16}$ 는 만성 목 통증이 있는 환자를 대상으로 멕켄지 운동을 실시한 결과 중재 후 통증 감소 및 두개척추 각을 증가시켰다고 하였다. 켄달의 운동법은 깊은 목 굽힘근들과 어 깨 들임근들의 근육을 강화하고 가슴근들을 스트레칭시켜 불안정 한 머리전방 자세를 바로잡아 목의 올바른 정렬에 도움이 된다고 하 였다. ${ }^{5}$ 이 두 가지 모두 전방머리자세의 자세 개선에 도움이 되는 운 동법이며, 이처럼 전방머리자세에 대한 근골격계 연구들은 많았으나 호흡기능에 관한 연구는 미흡한 실정이다.

이에 본 연구는 운동의 효과성이 입증된 멕켄지와 켄달의 운동을 수정하여 전방머리자세를 가진 대상자에게 수정된 경부운동을 적 용하였다. 이러한 프로그램을 통하여 수정된 경부운동이 전방머리 자세를 가진 대상자들에게 수정된 경부운동의 효율성과 호흡기능 개선에 영향을 미치는지를 알아보고자 한다.

\section{연구 방법}

\section{1. 연구대상}

본 연구는 강원도에 소재한 $\mathrm{K}$ 대학교에 재학중인 성인 남, 여 33 (남: 17명, 여: 16명)명을 대상으로 실험을 진행 하였다. A 그룹의 평 균나이는 $21.25 \pm 1.81$ 세, 평균 키는 $165.66 \pm 7.66 \mathrm{~cm}$, 평균체중은 60.50 $\pm 9.82 \mathrm{~kg}$ 였고, $\mathrm{B}$ 그룹의 평균나이는 $21.45 \pm 1.57$ 세, 평균 키는 $170.18 \pm$ $10.63 \mathrm{~cm}$, 평균체중은 $68.36 \pm 12.78 \mathrm{~kg}$ 였으며, 그리고 C 그룹의 평균나 이는 $22.10 \pm 2.33$ 세, 평균 키는 $169.00 \pm 8.32 \mathrm{~cm}$, 평균체중은 $66.40 \pm$ $12.47 \mathrm{~kg}$ 였다(Table 1). 실험을 실시하기 전 연구의 목적과 방법에 대하 여 설명을 들은 후 본 실험에 자발적으로 동의를 한 대상자에 한해 연구를 실시하였다. 대상자의 선정기준은 스마트폰을 사용하는 1년 이상인 자, 머리척추각(cranio vertebral angle, CVA)가 54도 이하인 자, 신경계 및 근골격계에 대한 병력이 없는 자, 어지러움증이나 균형장 애가 없는 자로 선정을 하였고, 전정기관에 문제가 있는 자, 연구에 영
Table 1. General characteristics of subjects $(N=33)$

\begin{tabular}{lccc}
\hline & A group & B group & C group \\
\hline M/F & $7 / 5$ & $7 / 4$ & $5 / 5$ \\
Age (year) & $21.25 \pm 1.81$ & $21.45 \pm 1.57$ & $22.10 \pm 2.33$ \\
Weight $(\mathrm{kg})$ & $60.50 \pm 9.82$ & $68.36 \pm 12.78$ & $66.40 \pm 12.47$ \\
Height $(\mathrm{cm})$ & $165.66 \pm 7.66$ & $170.18 \pm 10.63$ & $169.00 \pm 8.32$ \\
\hline
\end{tabular}

향을 주는 호흡기에 문제가 있는 자, 그리고 운동을 수행할 수 없는 자는 실험에서 제외를 하였다. 선정된 33명의 대상자는 무작위로 수 정된 경부 운동법을 하루에 1 번(A 그룹), 하루에 2 번(B 그룹), 하루에 3 번(C 그룹)을 적용하는 군으로 그룹을 나누었다.

\section{2. 실험방법}

\section{1) 중재방법}

수정된 경부 운동법은 턱을 목에 붙인 채 머리를 최대한 뒤쪽 방향 으로 천천히 끌어당기고 머리가 뒤로 젖혀지지 않도록 시선은 전방 을 향한다. 그리고 양손을 깍지 낀 후 머리 뒤쪽에 위치시키고 깍지 긴 방향으로 머리를 밀라고 요청하였다. 또한, 큰가슴근이 스트레칭 될 수 있도록 깍지 낀 손을 최대한 벌리도록 하였다. 그룹별 운동은 7 초 운동, 10 초 휴식을 1 회로 하여 5 회 1 셋트(set)를 기준으로 3 세트를 실시하였다. 오차를 줄이기 위하여 숙련된 물리치료사가 정확히 운 동할 수 있도록 지도하였으며, A그룹은 오전에 실시, B그룹은 오전, 오후에 실시하였고, 그리고 C그룹은 오전, 오후, 그리고 저녁에 실시 하였다. 1 주일에 5 회 실시하였으며 총 4 주간에 걸쳐 진행하였다.

\section{2) 측정도구}

(1) 머리척추각(craniovertebral angle, CVA)

$\mathrm{CVA}$ 의 각도는 귀구슬(tragus)의 중간 지점과 제7번 목뼈의 가시돌 기를 표시한 지점 사이를 잇는 선과 제7번 목뼈의 가시돌기 높이를 지나는 수평선이 이루는 각도이다. CVA가 작을수록 전방머리자세 가 심하다는 것을 의미한다. ${ }^{17}$ 대상자는 양팔을 체간 옆에 이완시킨 채로 바로 선 자세를 유지하도록 하였고, 시선은 대상자의 눈높이에 미리 지정된 지점을 향하도록 하였다. 사진을 찍었을 때 정확한 위치 를 측정하기 위해서 대상자의 귀구슬과 제7번 목뼈의 가시돌기 위치 를 각각 표시하였다. CVA를 측정하기 위하여 게이트뷰(GAITIVEW PRO 1.0, 알푸스, 한국)를 사용하였다. 게이트뷰의 기능 중 자세테스 트(posture test)를 이용하여 대상자를 촬영하였고, 크로스라인(crossline)을 이용하여 $\mathrm{CVA}$ 를 측정하였다.

\section{(2) 호흡기능(respiratory function)}

폐 기능 검사의 측정도구는 Spirometer (MicroQuark, Cosmed, Italy) 를 이용하여 노력성 폐활량(forced vital capacity, FVC), 1초간 노력성 
날숨량(forced expiratory volume at one second, FEV1), 느린 폐활량 (slow vital capacity, SVC), 그리고 최대 수의적 환기량(maximal voluntary ventilation, $\mathrm{MVV})$ 을 측정하였다.

측정 시 대상자는 등받이가 없는 의자에 앉아 5 분 정도 안정을 취 하게 하였다. 측정 시 공기의 손실을 최대한 줄이기 위하여 모든 대상 자는 코마개를 착용하였으며, 입으로만 호흡하도록 하였다. 정확한 측정을 하기 위해서 대상자가 이해할 수 있도록 충분한 설명과 시범 을 보여준 후에 실시를 하였다. 대상자에게 측정에 대한 설명을 자세 히 하고 마우스피스 적용 시 침 흘림이나 공기 빠짐 등을 최대한 통제 하여 정확도를 높이고자 하였으며, 측정마다 충분한 휴식을 취한 후 3 회를 반복 측정하여 평균값을 기록하였다.

노력성 폐활량은 천천히 최대한 숨을 깊이 들어 마신 후 최대한 빠 르게 세게 뱉는 공기의 최대양이다. 노력성 폐활량의 측정을 통해 제 한성 폐질환의 유무를 확인할 수 있다. 1초간 노력성 날숨량은 노력 성 폐활량 측정시 첫 1 초 동안에 불어낸 가스의 용적을 의미하고 1 초 간 노력성 날숨량의 측정을 통해 폐쇄성 질환에서 사용되는 평가지 수이며, 폐쇄성 질환은 기도가 좁기 때문에 이 지수의 값이 감소 한 다. ${ }^{18}$ 느린 폐활량은 가능한 최대한 천천히 공기를 들어 마신 후 최대 한 천천히 공기를 불어내는 방법으로, 노력성 호흡 방법으로 가능한 최대한 공기를 들여 마신 후, 최대한 느리고 길게 불어 낸 공기의 양 (L)을 의미한다. 최대 수의적 환기량은 호흡근의 근력 및 근지구력을 측정하기 위한 객관적이고 역동적인 측정 방법의 하나이며, ${ }^{19}$ 단위시 간 내에 자발적 노력으로 할 수 있는 최대의 환기량을 분당 들이마시 고 내신 공기의 양 $(\mathrm{L} / \mathrm{min})$ 으로 표시한 것으로, 가능한 크고, 빠르게 환기시켜서 측정한다. 본 연구에서는 12 초의 시간으로 측정을 하였 다. ${ }^{20}$

\section{3. 자료분석}

수집된 자료는 SPSS 18 PASW Statistics를 이용하여 통계처리 하였 다. 운동 전, 후 호흡기능 차이를 보기 위하여 대응표본 t-검정(paired t-test)을 하였고, 수정된 경부운동량의 그룹 간 차이를 보기 위하여 운동 전, 후의 차이 값을 이용하여 일요인 분산분석(one-way ANOVA)을 실시하였다. 사후검정으로 Bonferroni post-hoc을 이용하였으 며, 통계적 유의수준은 $\mathrm{p}<0.05$ 로 하였다.

\section{연구 결과}

\section{1. 훈련 전, 후 및 그룹 간 호흡기능 비교}

수정된 경부운동에 따른 4 주간의 중재 후 노력성 폐활량, 1 초간 노 력성 날숨량, 그리고 최대 수의적 환기량은 하루에 세 번 운동을 하 는 C 그룹에서 유의한 차이를 보였으며 $(\mathrm{p}<0.05)$, 최대 수의적 환기량
Table 2. Comparison of respiratory function between pre-test and post-test (Unit: L)

\begin{tabular}{llccc}
\hline \multirow{2}{*}{ group variable } & A group & B group & C group \\
\cline { 3 - 5 } & & \multicolumn{3}{c}{ Mean \pm SD } \\
\hline FVC & pre & $3.41 \pm 0.85$ & $4.42 \pm 0.98$ & $4.09 \pm 1.18$ \\
& post & $3.42 \pm 0.79$ & $4.50 \pm 0.98$ & $4.31 \pm 1.07$ \\
& t & -0.22 & -1.8 & $-3.66^{*}$ \\
FEV1 & pre & $2.86 \pm 0.93$ & $3.90 \pm 0.84$ & $3.54 \pm 1.10$ \\
& post & $3.01 \pm 0.83$ & $3.97 \pm 0.82$ & $3.74 \pm 1.03$ \\
& t & -1.02 & -1.28 & $-2.13^{*}$ \\
SVC & pre & $3.38 \pm 0.77$ & $4.36 \pm 1.16$ & $4.11 \pm 1.17$ \\
& post & $3.40 \pm 0.73$ & $4.38 \pm 1.08$ & $4.34 \pm 1.15$ \\
& t & -0.43 & -0.013 & -2.03 \\
MVV & pre & $88.17 \pm 26.62$ & $113.63 \pm 37.79$ & $103.41 \pm 38.82$ \\
& post & $96.98 \pm 30.30$ & $128.99 \pm 40.18$ & $119.55 \pm 35.31$ \\
& t & $-2.3^{*}$ & $-2.25^{*}$ & $-2.7^{*}$ \\
\hline
\end{tabular}

FVC: forced vital capacity, FEV1: forced expiratory volume at one second, SVC: slow vital capacity MVV: maximal voluntary ventilation. ${ }^{*} p<0.05$.

Table 3. Comparison of respiratory function among groups (Unit: L)

\begin{tabular}{lccccc}
\hline & $\begin{array}{c}\text { A group } \\
(n=12)\end{array}$ & $\begin{array}{c}\text { B group } \\
(n=11)\end{array}$ & $\begin{array}{c}\text { C group } \\
(n=10)\end{array}$ & $F$ & post-hoc \\
\hline FVC & $0.01 \pm 0.23$ & $0.07 \pm 0.13$ & $0.22 \pm 0.19$ & $3.34^{*}$ & A/C \\
FEV1 & $0.56 \pm 0.71$ & $0.60 \pm 0.28$ & $0.76 \pm 0.32$ & 0.49 & \\
SVC & $0.01 \pm 0.13$ & $0.01 \pm 0.43$ & $0.22 \pm 0.35$ & 1.46 & \\
MVV & $8.80 \pm 13.24$ & $15.35 \pm 22.58$ & $16.14 \pm 18.86$ & 0.54 & \\
\hline
\end{tabular}

FVC: forced vital capacity, FEV1: forced expiratory volume at one second, SVC: slow vital capacity MVV: maximal voluntary ventilation. ${ }^{*} \mathrm{p}<0.05$.

은 모든 그룹에서 유의한 차이를 보였다 $(\mathrm{p}<0.05)$. 수정된 경부운동의 그룹 간 운동량은 노력성 폐활량에서 유의한 차이를 보였으며 $(\mathrm{p}<0.05)$, 사후분석결과 하루에 한 번 운동하는 A 그룹과 하루에 세 번 운동을 하는 C 그룹에서 유의한 차이를 보였다 $(\mathrm{p}<0.05)($ Table 2,3$)$

\section{고 찰}

스마트폰은 휴대 전화 기능 뿐 만 아니라 인터넷 통신과 정보 검색 등 컴퓨터 기능을 지원함과 동시에 더불어 digital multimedia broadcating $(\mathrm{DMB})$ 기능으로 언제 어디서나 TV 방송 시청이 가능하고, ${ }^{21}$ 이 러한 작은 화면의 사용이 아래쪽으로 시선을 향하게 하여 보다 더 구 부정한 자세를 유발시킨다고 하였다.22 구부정한 자세는 전방머리자 세를 만들고 이로 인해 정상적인 척추 만곡을 유지하지 못하여 목과 어깨의 근 골격계의 문제를 야기한다. 따라서 잘못된 자세 습관과 일 상적인 생활패턴으로 인해 자세가 변형되어 가는 현대인들에게 올바 른 운동과 교육의 중요성이 강조되고 있다. 이에 본 연구는 스마트폰 을 사용하는 전방머리자세가 있는 대상자들에게 수정된 경부운동 
을 적용하여 운동의 효율성과 어느 정도의 운동량으로 호흡기능에 영향을 미치는지를 알아보고자 하였다.

수정된 경부운동은 운동의 효과성이 입증된 멕켄지와 켄달의 운 동을 조합하였으며, 4 주 동안 수정된 경부운동을 하루에 한 번 운동 하는 하는 그룹(A 그룹)과, 하루에 두 번(B 그룹), 그리고 하루에 세 번 운동하는 그룹(C 그룹)으로 나누었다.

연구 결과 노력성 폐활량은 하루에 세 번 운동을 하는 C 그룹에서 중재 전 $4.09 \pm 1.18$ 에서 중재 후 $4.31 \pm 1.07$ 로 유의하게 증가를 하였으 며, 나머지 두 그룹에서는 유의한 차이는 없었다. 운동량의 그룹 간 비 교에서는 하루에 한 번 운동을 하는 A그룹과 하루에 세 번 운동을 하 는 C 그룹에서 유의한 차이를 보였다. 이것은 하루에 한 번 운동을 하 는 것보다는 하루에 운동을 세 번 하는 것이 호흡기능의 개선됨을 보 여준다. 1초간 노력성 날숨량은 하루에 세 번 운동을 하는 C 그룹에서 중재 전 $3.54 \pm 1.10$ 에서 중재 후 $3.74 \pm 1.03$ 로 유의하게 증가를 하였고, 나머지 두 그룹에서는 유의한 차이는 없었으며, 운동량의 그룹 간 비 교에서도 유의한 차이가 없었다. Kapreli 등은 전방머리자세가 목뼈 와 등뼈의 해부학적인 구조를 변화시켜 가슴우리와 폐 기능을 변화시 킨다고 하였으며, $\operatorname{Kim}$ 등른 전방머리자세가 호흡기능의 약화를 유 발한다고 하였다. 또한, Okuro 등23은 전방머리자세가 1 초간 노력성 날 숨량의 감소와 함께 폐활량을 감소시키며 폐활량의 감소는 가로막의 가동성과 기능의 손상으로 이어져 복부근육을 비효율적으로 수축시 킨다고 하였다. 이러한 연구결과들은 자세의 변화가 호흡기능에 영향 을 미친다는 것을 단적으로 보여주는 것이다. 본 연구에서도 스마트 폰을 사용하는 전방머리자세를 가진 대상자들이 수정된 경부운동 을 한 후 호흡기능이 증가됨을 알 수 있었다. 이것은 전방머리자세를 가진 대상자들의 호흡기능이 저하되었음을 의미하는 것이다. 만성 목 통증이 있는 환자에게 전방머리자세와 같은 자세 변형과 관련된 호흡 기능의 저하가 나타날 수 있다고 하였다.,11 위의 연구 결과를 보면 전 방머리자세를 가진 대상자들이 수정된 경부운동을 통하여 호흡기능 이 향상됨을 알 수 있었다. 수정된 경부운동은 8 분 정도의 짧은 시간 이 소요되었으며, 짧은 시간임에도 불구하고 호흡기능의 개선을 보였 으며, 수정된 경부운동을 하루에 한 번 운동을 하는 것보다 하루에 세 번 운동을 할 때 더욱 많은 호흡기능의 개선을 보였다.

느린 폐활량은 중재 후 유의한 차이는 없었으며, 운동량의 그룹 간 비교에서도 유의한 차이가 없었다. 폐 기능 검사에서 폐활량은 폐쇄 성 폐질환의 환기장애가 있다 하더라도 천천히 숨을 내쉬는 경우 비 교적 정상으로 나타날 수 있으므로 진단에 제약이 있고, 급성 악화 혹은 환자의 의도에 의하여 협조가 이루어 지지 않는 경우는 측정하 기 어렵다는 단점이 있다고 하였다. ${ }^{24}$ 본 연구 결과 또한 이러한 원인 으로 인하여 느린 폐활량의 중재 후 변화가 없는 것처럼 나타났다. 그 리고 최대 수의적 환기량은 중재 전, 후 모든 그룹에서 유의한 차이를
보였으며, 운동량의 그룹간 비교에서는 유의한 차이가 없었다. Quanjer 등25은 흥벽과 폐의 확장과 수축 시에 내재된 저항에 대한 총체적 일 용량을 의미하는 호흡근의 근지구력을 간접적으로 평가할 수 있 다고 하였고, Kapreli 등은 최대 수의적 환기량이 호흡근의 약화와 신 경근육질환(neuromuscular disorder)의 가장 민감한 지표라고 하였다. 연구 결과 또한 중재 후 모든 그룹에서 유의한 차이를 보인 것은 전방 머리자세를 가진 대상자들의 폐활량의 저하를 의미하며 약 12 초의 반복적인 최대 들숨노력과 최대 날숨노력을 사용하는 최대 수의적 환기량의 증가는 수정된 경부운동이 전방머리자세를 개선시킴과 동 시에 이 운동을 통해 호흡기능이 향상된 것으로 추정된다.

본 연구에서 실시한 수정된 경부운동은 목의 폄 운동과 가슴근의 신장운동을 동시에 실시하였다. 턱을 머리 뒤쪽으로 끌어당기고, 뒤 쪽으로 압력을 주어 더욱 강하게 경부의 심부근(cervical deep muscle) 을 강화를 하였다. 또한, 머리 뒤로 깍지를 하고 깍지 낀 손을 더욱 벌 리게 하여 최대한으로 가슴근육을 신장되게 만들었다. 이 자세는 가 슴근의 신장뿐만이 아니라 견부(scapular)의 후인근육(retractor muscle)을 강화시키는 역할까지 한다. $\mathrm{Kim}^{12}$ 은 멕켄지 운동이 전방머리자 세와 호흡 기능에 관한 연구에서 중재 후 FVC, $\mathrm{FVC}$ 의 \%예측치, $\mathrm{FEV} 1, \mathrm{FEV} 1$ 의 \%예측치가 유의하게 개선되었다고 하였으며, Har$\operatorname{man}^{26}$ 은 10 주간 Kendall운동을 적용하여 치료군과 통제군을 비교한 연구에서 전방머리자세가 Kendall운동에 효과가 있음을 입증하였 다. 본 연구 또한 수정된 경부운동이 전방머리자세를 가진 대상자들 에게 호흡기능을 개선시키는 유용한 운동임을 증명할 수 있었다.

수정된 경부운동은 간단하면서도 대상자들도 따라 하기 쉬운 운 동이다. 그래서 바쁜 일상 생활로 인하여 운동할 시간이 적은 현대인 들에게 많은 시간을 투자할 필요 없이 잠깐의 운동으로 전방머리자 세 및 호흡기능을 개선시키는 데 효과적인 운동임을 알 수 있었다. 따 라서 기존에 목 통증을 감소시키고, 관절가동범위를 증가시키는 것 으로 알려진 멕켄지 운동과 켄달의 운동법을 조합한 수정된 경부운 동법이 전방머리자세가 있는 사람들의 호흡 기능을 개선시키는데 기 여할 것으로 사료된다.

본 연구는 환자가 아닌 일반인을 대상으로 하였기에 일반화 하기 에는 어려움이 있다. 그리고 참여한 대상자의 수가 적었으며, 운동의 중재기간이 짧았다. 따라서 향후 연구에서는 환자를 대상으로 한 연 구와 참여 대상자의 수 및 충분한 중재기간을 두어 호흡기능의 효과 에 대한 후속연구가 필요할 것으로 사료된다

\section{참고 문헌}

1. Ministry of science, ict and future planning. Subscriber statistics of wired and wireless communication services. 2015; Rep of Korea.

2. National health insurance service. Press release of cervical disk, the recent 
rate of increase in five years 20s. 2013; Rep of Korea.

3. Hickey ER, Rondeau MJ, Corrente JR et al. Reliability of the cervical range of motion device and plumb-line techniques in measuring resting head posture. Journal of Manual\& Manipulative Therap. 2000;8(1):10-7.

4. Janwantanakul P, Sitthipornvorakul E, Paksaichol A. Risk factors for the onset of nonspecific low back pain in office workers: a systematic review of prospective cohort studies. J Manipulative Physiol Ther. 2012;35(7):568-77.

5. Kendall FP, Elizabeth KM, Patricia GP. Muscles: testing and function. baltimore: Williams\&Wilkins. 1993.

6. Harrison DE, Harrison DD, Betz JJ et al. Increasing the cervical lordosis with chiropractic biophysics seated combined extension-compression and transverse load cervical traction with cervical manipulation: Nonrandomized clinical control trial. J Manipulative Physiol Ther. 2003; 26(3):139-51.

7. Kapreli E, Vourazanis E, Strimpakos N. Neck pain causes respiratory dysfunction. Med Hypotheses. 2008;70(5):1009-13.

8. Kapreli E, Vourazanis E, Billis E et al. Respiratory dysfunction in chronic neck pain patients. A pilot study. Cephalalgia. 2009;29(7):701-10.

9. Quek J, Pua YH, Clark RA et al. Effects of thoracic kyphosis and forward head posture on cervical range of motion in older adults. Man Ther. 2013;18(1):65-71.

10. Dimitriadis Z, Kapreli E, Strimpakos N et al. Respiratory weakness in patients with chronic neck pain. Man Ther 2013. 2013;18(3):248-53.

11. Perri MA, Halford E. Pain and faulty breathing: a pilotstudy. J Bodyw MovTher. 2004;8(4):297-306.

12. Kim SY, Kim NS, Jung JH et al. Effect of forward head posture on respiratory function in young adults. J Kor Phys Ther. 2013;25(5):311-5.

13. Silveira Wd, Mello FC, Guimarães FS et al. Postural alterations and pulmonary function of mouth-breathing children. Braz J Otorhinolaryngol. 2010;76(6):683-6.

14. Janda V. Muscle and motor control in cervicogenic disorders, in physical therapy of the cervical and thoracic spine. Churchill LivingstoneEdinburgh. 1994:195-216.

15. McKenzie R. Treat your own neck. Raumati Beach (New Zealand): Spi- nal publications. 1983.

16. Jung YW. Effects of mckenzie exercise on the functional recovery and forward head posture of chronic neck pain patients. J Korean Soc Phys Med. 2006;1(1):93-108.

17. Raine S, Twomey LT. Head and shoulder posture variations in 160 asymptomatic women and men. Arch Phys Med Rehabil. 1997;78(11): 1215-23.

18. Han JT, Go MJ, Kim YJ. Comparison of forced vital capacity and maximal voluntary ventilation between normal and forward head posture. J Korean Soc Phys Med. 2015;10(1):83-9.

19. Neder JA, Andreoni S, Lerario MC et al. Reference values for lung function tests. Ii. Maximal respiratory pressures and voluntary ventilation. Braz J Med Biol Res. 1999;32(6):719-27.

20. Heliopoulos I, Patlakas G, Vadikolias K et al. Maximal voluntary ventilation in myasthenia gravis. Muscle Nerve. 2003;27(6):715-9.

21. Bae JK, Jeong HM. An empirical study on the determinants factors by including functional attributes of smart phone adoption. The e-Business Studies. 2008;9(4):337-61.

22. Greig AM, Straker LM, Briggs AM. Cervical erector spinea and upper trapezius muscle activity in children using different information technologies. physio ther. 2005;91(2):119-26.

23. Okuro RT, Morcillo AM, Ribeiro MÂ et al. Mouth breathing and forward head posture: effects on respiratory biomechanics and exercise capacity in children. J Bras Pneumol. 2011;37(4):471-9.

24 . The korean academy of tuberculosis and respiratory diseases. Pneumology. Seoul: KOONZA. 2004.

25. Quanjer PH, Tammeling GJ, Cotes JE et al. Lung volumes and forced ventilatory flows. report working party standardization of lung function tests, european community for steel and coal. official statement of the european respiratory society. Eur Respir J Suppl. 1993;16:5-40.

26. Harman K, Hubley-Kozey CL, Butler H. Effectiveness of an exercise program to improve forward head posture in normal adults: a randomized,controlled 10-week trial. J Manipulative Physio Ther. 2005; 13(3):163-76 